$A H B: \operatorname{MAP}$

$\mathrm{IV}-4$

SUPPLEMENT TO CIRCULAR LETTER NO, 32

The following rethod for silvering swall glass surfaces is being successfully used by the optical Instruments Section of the Burear of Standards.

\title{
Silvering Solution
}

Dissolve 31.10 grams silver nitrate in $35 \mathrm{cc}$ distilled water. And $15.55 \mathrm{cc}$ potassiur hydroxide (purified by alcohol) is dissolved in $30 \mathrm{cc}$ distilled water.

Add 31 cc silver nitrate solution to 3785.4 co distilled water. Then add armonia, drop by drop, until the precipitate is formed. Stir the solution well. Armonia is again added, drop by drop, and the solution is stirred continuously until nearly clear.

Having the solution at this point, add the $30 \mathrm{cc}$ potassiur hyciroxide solution; and continue adding arilonia as before. Stir and add armonia until the whole solution is nearly clear. Add the remining $6.5 \mathrm{cc}$ silver nitrate solution.

\section{Peducing Solution}

Dissolfe 200.95 grams cane sugar in $2839 \mathrm{cc}$ distilled rater. Add 7.30 co nitric acid, C.P. Stir. Add 236.6 co grain alcohol. Stir.

This solution improves with age, and when used should be at least one month old.

The reducing solution, silvering solution, and distilled water are placed in three separate botties, $B_{1}, B_{2}$ and $B_{3}$. Glass syphon tubes, each of which is fitted with two stop-cocks, extend from each of the bottles. The upper stop-cocks, $S_{I}, S_{Z}$ and $S_{3}$, are set perranently to give the desired rate of flow of each solution. This rate of flow is is follows: 80 drops of silvering solution, 16 drops of reducing solution, and 80 drops of distilled water per rinute. 

The solutions cirop from the tubes into a slass funnel F where they becoire rixed. The glass $G$ to be silvered is rlaced about an inch below the funnel. While the process is going on trie funnel should be roved so that the liquid is unifornly distributed over the level surface of the glass. The sfent solution flows into a receptacle rinich is placed beneath the lass. The glass to be silvered and the receptacle are placed on the levelling table $T$, in order that the surface of the glass ray be easily levelled.

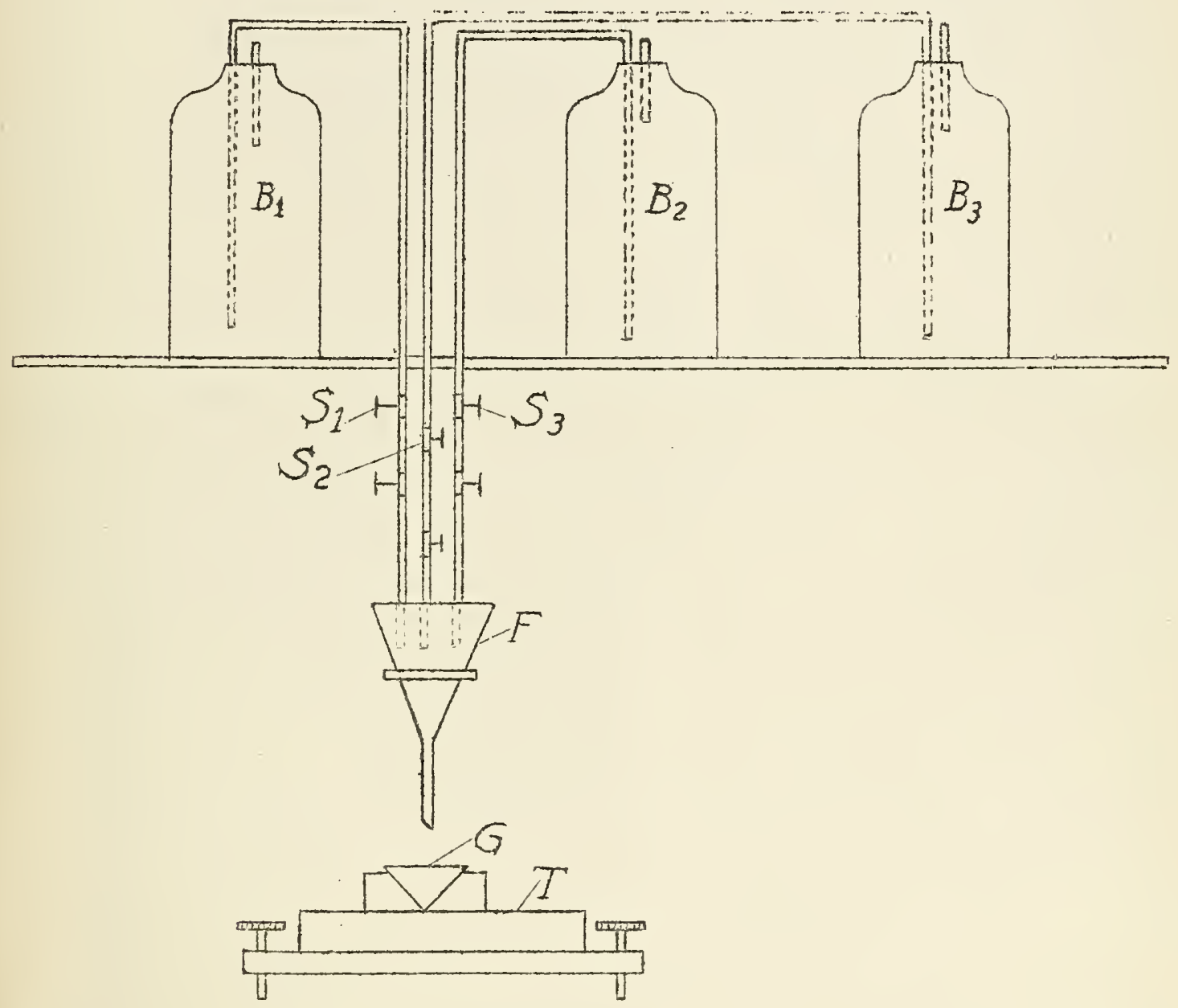

\section{Cleaning the Glass for Bilverinf}

The surface of the filas should be cleaned itith raphtha, nitric acid, armonia, then nitric acid, and finally distilled water, in the order named. The surface should not be allowed to dry betreen cleanirg and silvering. 

